\title{
BPI fold-containing family a member 2 as a biomarker of acute kidney injury-close but no (clinical) cigar?
}

\author{
Patrick M. Honore ${ }^{1}$, David De Bels ${ }^{1}$, Herbert D. Spapen ${ }^{2}$ \\ ${ }^{1}$ Department of Intensive Care, Centre Hospitalier Universitaire Brugmann, Brussels, Belgium; ${ }^{2}$ Department of Intensive Care Unit, Universitair \\ Ziekenhuis Brussel, VUB University, Brussels, Belgium \\ Correspondence to: Prof. Patrick M. Honore, MD, PhD. Department of Intensive Care, Centre Hospitalier Universitaire Brugmann, 4, Place Van \\ Gehuchten, 1020 Brussels, Belgium. Email: Patrick.Honore@CHU-Brugmann.be. \\ Provenance: This is a Guest Editorial commissioned by Section Editor Bing Gu, MD (Department of Laboratory Medicine, the Affiliated Hospital of \\ Xuzhou Medical University, Xuzhou, China). \\ Comment on: Kota SK, Pernicone E, Leaf DE, et al. BPI fold-containing family a member 2/parotid secretory protein is an early biomarker of AKI. J \\ Am Soc Nephrol 2017;28:3473-8.
}

Submitted Feb 07, 2018. Accepted for publication Mar 07, 2018.

doi: 10.21037/atm.2018.03.13

View this article at: http://dx.doi.org/10.21037/atm.2018.03.13

Acute kidney injury (AKI) affects up to $50 \%$ of critically ill patients and is independently associated with both short and long-term mortality (1). Early identification of AKI is the main impulse for AKI biomarker research. Biomarkers are complementary to functional tests and, in addition, may be used to optimize AKI staging, to direct intervention, and to predict prognosis. Over the last decade, various AKI biomarkers have emerged: neutrophil gelatinase-associated lipocalin (NGAL), cystatin C, kidney injury molecule-1, monocyte chemotactic peptide-1, $\mathrm{N}$-acetyl- $\beta$-D-glucosaminidase, interleukin-18, liver-type fatty acid-binding protein, netrin-1, endogenous ouabain, selenium-binding protein 1 , and the cell cycle arrest initiating proteins tissue inhibitor of metalloproteinases-2 (TIMP-2) and insulin-like growth factor binding protein-7 (IGFBP-7) (2).

Kota et al. furnish ample and well-documented molecular, genetic, and clinical proof to adopt BPI fold-containing family A member 2 (BPIFA2) as a novel sensitive AKI biomarker. They assessed the utility of BPIFA2 in different mouse models of AKI (ischemia reperfusion, drug-induced, and endotoxemic $\mathrm{AKI}$ ) and in patients with AKI of diverse origin (acute tubular necrosis, renal failure post-cardiac surgery, hepatorenal syndrome, and contrast nephropathy) (3). BPIFA2 expression was induced early in both murine and human kidneys and BPIFA2 protein became readily detectable in urine and plasma following AKI. Such dynamic and kidney-specific expression pattern led the authors to propose BPIFA2 as an attractive biomarker for early diagnosis and monitoring of AKI.

Apart from molecular typing and categorizing, BPIFA2 has not been extensively studied. BPIFA2 (or parotid secretory protein) is one of the mammalian lipid-binding bactericidal/permeability-increasing protein (BPI) fold-containing glycoproteins formerly known as palate, lung and nasal epithelium clone (PLUNC) proteins. There are currently six BPIFA families. The BPIFA2 family is by far the most diverse and complex entity, with two lineage-specific duplications and low pairwise identities between the remaining members (4). Sharing structure similarity, BPIFA peptides are functionally related to BPI. BPI is a 456-residue cationic protein stored in leukocytes with potent anti-endotoxin activity and highly selective bactericidal effects on Gram-negative bacteria $(5,6)$. PLUNC proteins, in general, are involved in local antibacterial responses in the upper and proximal respiratory tract of air-breathing mammals. However, unlike the BPI fold-containing BPIFA1 protein which has well-determined immunoregulatory, antibacterial, and host-protective capabilities (7), information on similar or comparable BPIFA2 actions is extremely scarce (8).

Biomarkers of AKI are theoretically useful in any type of AKI. In clinical practice, however, sensitive 
biomarkers are of crucial importance for early detection and monitoring of sepsis-induced AKI. Sepsis is characterized by a dysregulated immune-inflammatory host response to infection resulting in life-threatening organ failure (9). Up to $50 \%$ of patients with severe sepsis and septic shock develop AKI (10). Whether BPIFA2 would be a good marker of sepsis-induced AKI is insufficiently supported by the study of Kota $\mathrm{et} \mathrm{al}$. models of renal ischemia are not relevant to the pathophysiology of septic AKI (11). In the absence of global hypoperfusion, septic AKI more likely has a functional (glomerular) rather than an injurious (tubular) origin (12). The complexity and mutual interaction of molecular mechanisms underlying septic AKI furthermore clouds insight into BPIFA2 behaviour. Moreover, the presence of AKI in se mediates a systemic inflammatory response that causes remote damage in heart, lung, brain, spleen, liver, and gut (13). The BPI superfamily probably plays an active, yet undetermined, role in this process. Of note is that, despite its thoroughly documented antiinflammatory and antimicrobial potential, BPI has not gained major biomarker importance (14). In a large cohort of patients with suspected infection, BPI performed poorly as predictor of severe sepsis (15).

Kota et al. demonstrated that BPIFA2 allowed adequate detection of kidney "stress" or "damage" in patients with established AKI (3). It remains to be proven whether BPIFA2 may adequately predict AKI development or severity. Such potential has been clinically demonstrated for the (TIMP-2).(IGFBP-7) biomarker panel. In critically ill patients, urinary (TIMP-2).(IGFBP-7) highly predicted evolution to moderate and severe AKI. (TIMP-2).(IGFBP-7) was significantly superior to all previously described markers of $\mathrm{AKI}$ and improved risk stratification when added to a nine-parameter clinical model (16). A single urinary (TIMP-2) (IGFBP-7) test also accurately predicted early development and severity of AKI in high-risk postoperative (17), post cardiac surgery (18), and septic (19) patients.

An increasing number of critically ill patients suffering $\mathrm{AKI}$, and in particular those with septic AKI, will receive renal replacement therapy. Continuous techniques have progressively supplanted intermittent dialysis. Substances are expected to be removed by continuous hemodiafiltration when their molecular weight (MW) lies below the 30-35 kDa MW cut-off point of "classic" dialysis membranes (20). In addition, removal may be boosted when highly adsorptive dialysis membranes are employed (21). This has been shown for inflammatory peptides (monomeric
C-reactive protein and procalcitonin) and cytokines $(22,23)$ as well as AKI biomarkers (e.g., NGAL) (24). The BPIFA2 forms identified in circulation have a $\mathrm{MW}$ of 15 and $18 \mathrm{kDa}(3)$ and thus must stand the "test of continuous renal epuration" before being implemented as a valuable diagnostic and prognostic marker.

Biomarkers are increasingly embraced as important adjuvant tools for refining diagnosis, optimizing treatment, and predicting prognosis of AKI. AKI biomarker research advances by giant leaps. BPIFA2 certainly represents one more promising marker arising from the molecular pipeline. However, its validity in critically ill postoperative and septic patients who present with varying degrees of inflammation and concomitant evolving organ dysfunction or failure remains to be proven.

\section{Acknowledgements}

None.

\section{Footnote}

Conflicts of Interest: The authors have no conflicts of interest to declare.

\section{References}

1. Joannidis M, Druml W, Forni LG, et al. Prevention of acute kidney injury and protection of renal function in the intensive care unit: update 2017: Expert opinion of the Working Group on Prevention, AKI section, European Society of Intensive Care Medicine. Intensive Care Med 2017;43:730-49.

2. Beker BM, Corleto MG, Fieiras C, et al. Novel acute kidney injury biomarkers: their characteristics, utility and concerns. Int Urol Nephrol 2018;50:705-13.

3. Kota SK, Pernicone E, Leaf DE, et al. BPI Foldcontaining family a member 2 parotid secretory protein is an early biomarker of AKI. J Am Soc Nephrol 2017;28:3473-8.

4. Bingle CD, Seal RL, Craven CJ. Systematic nomenclature for the PLUNC/PSP/BSP30/SMGB proteins as a subfamily of the BPI fold-containing superfamily. Biochem Soc Trans 2011;39:977-83.

5. Weiss J, Elsbach P, Shu C, et al. Human bactericidal/ permeability-increasing protein and a recombinant $\mathrm{NH} 2-$ terminal fragment cause killing of serum-resistant gramnegative bacteria in whole blood and inhibit tumor 
necrosis factor release induced by the bacteria. J Clin Invest 1992;90:1122-30.

6. Elsbach P. The bactericidal/permeability-increasing protein (BPI) in antibacterial host defense. J Leukoc Biol 1998;64:14-8.

7. Britto CJ, Cohn L. Bactericidal/Permeability-increasing protein fold-containing family member A1 in airway host protection and respiratory disease. Am J Respir Cell Mol Biol 2015;52:525-34.

8. Abdolhosseini M, Sotsky JB, Shelar AP, et al. Human parotid secretory protein is a lipopolysaccharide-binding protein: identification of an anti-inflammatory peptide domain. Mol Cell Biochem 2012;359:1-8.

9. Singer M, Deutschman CS, Seymour CW, et al. The Third International Consensus Definitions for Sepsis and Septic Shock (Sepsis-3). JAMA 2016;315:801-10.

10. Bellomo R, Kellum JA, Ronco C, et al. Acute kidney injury in sepsis. Intensive Care Med 2017;43:816-28.

11. Langenberg C, Bagshaw SM, May CN, et al. The histopathology of septic acute kidney injury: A systematic review. Crit Care 2008;12:R38.

12. Maiden MJ, Otto S, Brealey JK, et al. Structure and function of the kidney in septic shock. A prospective controlled experimental study. Am J Respir Crit Care Med 2016;194:692-700.

13. Ologunde R, Zhao H, Lu K, et al. Organ cross talk and remote organ damage following acute kidney injury. Int Urol Nephrol 2014;46:2337-45.

14. Balakrishnan A, Marathe SA, Joglekar M, et al. Bactericidal/permeability increasing protein: a multifaceted protein with functions beyond LPS neutralization. Innate Immun 2013;19:339-47.

15. Uusitalo-Seppälä R, Peuravuori H, Koskinen P, et al. Role of plasma bactericidal/permeability-increasing protein, group IIA phospholipase A(2), C-reactive protein, and white blood cell count in the early detection of severe sepsis in the emergency department. Scand J Infect Dis

Cite this article as: Honore PM, De Bels D, Spapen HD. BPI fold-containing family a member 2 as a biomarker of acute kidney injury—close but no (clinical) cigar? Ann Transl Med 2018;6(10):191. doi: 10.21037/atm.2018.03.13
2012;44:697-704.

16. Kashani K, Al-Khafaji A, Ardiles T, et al. Discovery and validation of cell cycle arrest biomarkers in human acute kidney injury. Crit Care 2013;17:R25.

17. Gunnerson KJ, Shaw AD, Chawla LS, et al. Sapphire Topaz investigators. TIMP2 $\bullet$ IGFBP7 biomarker panel accurately predicts acute kidney injury in high-risk surgical patients. J Trauma Acute Care Surg 2016;80:243-9.

18. Wang Y, Zou Z, Jin J, et al. Urinary TIMP-2 and IGFBP7 for the prediction of acute kidney injury following cardiac surgery. BMC Nephrol 2017;18:177.

19. Honore PM, Nguyen HB, Gong M, et al. Sapphire and Topaz Investigators. Urinary Tissue Inhibitor of Metalloproteinase-2 and Insulin-Like Growth FactorBinding Protein 7 for risk stratification of acute kidney injury in patients with sepsis. Crit Care Med 2016;44:1851-60.

20. Honoré PM, Jacobs R, De Waele E, et al. Evaluating sepsis during continuous dialysis: are biomarkers still valid? Blood Purif 2014;38:104-5.

21. Honore PM, Jacobs R, Joannes-Boyau O, et al. Newly designed CRRT membranes for sepsis and SIRS-A pragmatic approach for bedside intensivists summarizing the more recent advances: A systematic structured review. ASAIO J 2013;59:99-106.

22. Dahaba AA, Elawady GA, Rehak PH, et al. Procalcitonin and proinflammatory cytokine clearance during continuous venovenous haemofiltration in septic patients. Anaesth Intensive Care 2002;30:269-74.

23. Honoré PM, Jacobs R, De Waele E, et al. Biomarkers of inflammation during continuous renal replacement therapy: sensors, players, or targets? Blood Purif 2014;38:102-3.

24. Donadio C. Dialysis with high-flux membranes significantly affects plasma levels of neutrophil gelatinaseassociated lipocalin. Crit Care 2016;20:20. 